\title{
Eclampsia: Still a major problem in rural KwaZulu-Natal Province, South Africa
}

\author{
V Makhanya, MB ChB, FCOG; J Moodley, MB ChB, FCOG, FRCOG, MD; L Govender, MB ChB, FCOG
}

Women's Health and HIV Research Group, Department of Obstetrics and Gynaecology, College of Health Sciences, University of KwaZulu-Natal, Durban, South Africa

Corresponding author: J Moodley (jmog@ukzn.ac.za)

Background. Eclampsia is a major direct cause of maternal mortality in South Africa (SA). Most cases of morbidity and mortality are probably due to late booking for antenatal care, poor quality of care and poor interfacility transport. Publications on eclampsia in SA are mainly from tertiary hospitals and often do not provide clinical management details at the referring hospital.

Objective. To describe the obstetric outcomes of eclampsia in a rural area of KwaZulu-Natal (KZN) Province.

Methods. This was a chart review of cases of eclampsia admitted to a regional health facility serving 19 maternity clinics and 17 district hospitals in northern KZN.

Results. There were 58 cases of eclampsia with complete data during the 6-month study period. Forty-nine women had booked for antenatal care, of whom $11(22.4 \%)$ had risk factors including persistent proteinuria and haematuria. Of the 11, $2(18.1 \%)$ had gestational hypertension well controlled on methyldopa and managed on an outpatient basis, and 2 with mild to moderate pre-eclampsia on two different types of antihypertensive agents were being treated as outpatients; 3 (27.2\%) of these had uncontrolled blood pressure levels on two repeated antenatal visits.

Conclusion. This clinical audit indicates that a number of cases of eclampsia could have been avoided if clinical protocols had been followed and timeous delivery and/or referrals had been considered.

S Afr J Obstet Gynaecol 2016;22(1):13-17. DOI:10.7196/SAJOG.v22i1.1034

Eclampsia, a major cause of maternal mortality and morbidity, is one of the subdivisions of the pre-eclampsia syndrome. The syndrome is peculiar to human pregnancies and is classified as gestational hypertension, pre-eclampsia, eclampsia and HELLP (Haemolysis, Elevated Liver enzyme and Low Platelet levels) syndrome. ${ }^{[1,2]}$ The common presenting clinical signs are hypertension and proteinuria, detected for the first time during the antenatal period, in labour or the immediate puerperium. Eclampsia is one of the endpoints of pre-eclampsia and is associated with the development of seizures. ${ }^{[1,2]}$

The latest Saving Mothers Report (SMR) (2011 - 2013) ${ }^{[3]}$ indicates that eclampsia accounts for $\sim 50 \%$ of deaths due to hypertensive disorders of pregnancy (HDP). In addition, HDP account for $\sim 15 \%$ of all maternal deaths in South Africa (SA) ${ }^{[3]}$ In high-income countries (HICs) eclampsia is associated with a low maternal death rate of $0.1 \% .^{[1,2]}$ The low incidence of eclampsia and low morbidity and mortality rates in HICs are probably due to easy access to antenatal care, good transport systems and populations fully informed of the benefits of healthcare during pregnancy, childbirth and the puerperium. In poor countries, multiple factors, including poor access to health facilities, particularly in rural areas, present a major challenge and probably account for the high morbidity and mortality rates. ${ }^{[1-3]}$ In addition, the SMR suggests that lack of resources including intensive care unit (ICU) facilities and inadequate resuscitation skills are factors that play a role in the morbidity and mortality associated with eclampsia. ${ }^{[3]}$ Because most publications on deaths associated with eclampsia in SA are based on data reported from tertiary hospitals, we decided to perform a clinical audit of the outcome of patients with eclampsia in a deep rural area of KwaZulu-Natal (KZN) Province, SA.

\section{Methods}

Following regulations including ethical permissions (BE: 401/13), we performed a retrospective chart review. Names of patients with the diagnosis of eclampsia were identified from the 'birth register' and information retrieved from the relevant hospital records. Where possible this was done on a daily basis during the study period. The clinical data were recorded on a pre-designed, structured data sheet.

The study site was a regional hospital situated in a rural area of northern KZN which serves as a referral base for 17 district hospitals and 19 local maternity clinics. The majority of referring facilities were at vast distances from the base hospital and access by ambulances was made difficult by poor roads and inadequate ambulance services. The management of eclampsia at the study site and the referring health facilities followed the recommendations of the Maternity Care Guidelines for Clinics and District Hospitals in SA. ${ }^{[4]}$ Briefly, this involves immediate resuscitative measures, administration of magnesium sulphate parenterally to prevent further seizures and the use of rapid-acting antihypertensive agents (labetalol and oral nifedipine) to reduce sustained high blood pressure levels of $\geq 160 \mathrm{mmHg}$ systolic and/or $\geq 110 \mathrm{mmHg}$ diastolic. Intensive monitoring of the mother and fetus is to continue while awaiting the ambulance, or until and after childbirth. ${ }^{[1,2,4]}$

\section{Results}

There were 60 patients diagnosed with eclampsia during the 6-month study period (February - July 2013); two files were missing, therefore the data on 58 patients were analysed. Forty-one patients were referred from district hospitals, and of these, 37 were booked and 4 unbooked; the clinics referred 14 patients, 12 of whom were booked, and 3 women were admitted directly from their places of residence and had had no antenatal care. 
The mean (standard deviation (SD)) age was 20.2 (4.8) years (range $13-38) ; 60.3 \%(n=35)$ were below the age of 19 . The majority were in the 16 - 24-year age group (Table 1 ). The median parity was 1 (range 0 - 3); 40 (69.0\%) of the patients were primigravidae.

\section{Antenatal care}

Forty-nine (84.5\%) patients had 'booked' for antenatal care, with a median number of visits of 4 (range 1 - 7) visits. Of the 49 booked patients, $11(22.4 \%)$ had risk factors during the antenatal care. Nine (15.5\%) patients did not attend antenatal care (not booked), 4 of whom were from district hospitals, 2 from local clinics and 3 from home.

Among 11 patients with risk factors in the antenatal period, $4(36.4 \%)$ had persistent proteinuria and haematuria, and 2 (18.2\%)

Table 1. Clinical data of all patients with eclampsia $(N=58)$

\begin{tabular}{|c|c|}
\hline Variables & $n(\%)^{*}$ \\
\hline Age groups $(y r)^{\dagger}$ & $20.2(4.8) ; 13-38$ \\
\hline$\leq 15$ & $3(5.2)$ \\
\hline $16-19$ & $32(55.2)$ \\
\hline $20-24$ & $13(22.4)$ \\
\hline $25-29$ & $6(10.3)$ \\
\hline $30-34$ & $3(5.2)$ \\
\hline$\geq 35$ & $1(1.7)$ \\
\hline \multicolumn{2}{|l|}{ Parity } \\
\hline 0 & $40(69.0)$ \\
\hline 1 & $13(22.4)$ \\
\hline 2 & $4(7.0)$ \\
\hline 3 & $1(1.6)$ \\
\hline \multicolumn{2}{|l|}{ Laboratory investigations ${ }^{\dagger}$} \\
\hline Haemoglobin $(\mathrm{g} / \mathrm{dL})$ & $11.0(2.6) ; 5.9-18.6$ \\
\hline Platelets $\left(\times 10^{9} / \mathrm{L}\right)$ & 209.2 (100.6); $38-553$ \\
\hline Serum urea $(\mathrm{mmol} / \mathrm{L})$ & $3.7(2.23) ; 0.2-10.5$ \\
\hline Serum creatinine $(\mu \mathrm{mol} / \mathrm{L})$ & $97.6(39.5) ; 40-279$ \\
\hline $\operatorname{ALT}(\mathrm{U} / \mathrm{L})$ & 86.3 (101.1); 20 - 282 \\
\hline $\mathrm{LDH}(\mathrm{U} / \mathrm{L})$ & 305.3 (458.1); $13-1200$ \\
\hline \multicolumn{2}{|l|}{ HIV status } \\
\hline Positive & $7(12.0)$ \\
\hline Negative & $48(82.8)$ \\
\hline Unknown & $3(5.2)$ \\
\hline $\begin{array}{l}\text { ALT = alanine transaminase; } \mathrm{LDH}=\text { lact } \\
{ }^{*} \text { Unless otherwise stated. } \\
{ }^{+} \text {Mean (SD); range. }\end{array}$ & \\
\hline
\end{tabular}

Table 2. Risk factors and substandard care in antenatal (booked) patients $(N=11)$

\begin{tabular}{lll}
\hline Risk factors during antenatal care & $\boldsymbol{n ( \% )}$ & Substandard care \\
\hline Gestational hypertension on methyldopa & $2(18.2)$ & \\
Persistent haematuria and proteinuria & $4(36.4)$ & $\begin{array}{l}\text { No 24-hour urine } \\
\text { protein/no urine } \\
\text { microscopy }\end{array}$ \\
& & $\begin{array}{l}\text { Managed as } \\
\text { outpatients }\end{array}$ \\
$\begin{array}{l}\text { Pre-eclampsia on two antihypertensive } \\
\text { agents }\end{array}$ & $2(18.2)$ & Not admitted to hospital
\end{tabular}

had gestational hypertension, well controlled on methyldopa. Two (18.2\%) patients diagnosed with mild to moderate pre-eclampsia on two different types of antihypertensive agents were being treated as outpatients (Table 2) with poor blood pressure control. Three (27.3\%) had uncontrolled blood pressure on all visits.

\section{Occurrence of convulsions}

Fifty-two (89.7\%) patients had convulsions in the antepartum period, $5(8.6 \%)$ in the intrapartum period and $1(1.7 \%)$ in the postpartum period. The median number of convulsions was 3 (range 1 - 10).

\section{Blood and urine investigations at referring facility}

Fifty-three (91.4\%) were referred from the district hospitals and clinics. Twenty-five (47.2\%) patients had blood investigations and 30 (56.6\%) had urine dipsticks estimations at the referring institutions. Monitoring of vital signs was done in $35(66.0 \%)$ patients prior to referral to the study site. Five $(8.6 \%)$ patients went directly to the regional hospital from home.

Table 3 shows the comparison of treatment at the referring facility and at the regional hospital.

\section{Management of eclampsia prior to referral}

At the referring site, 17 (29.3\%) of the patients were managed by midwives and $36(62.0 \%)$ by medical officers. The mode of transport

Table 3. Comparisons of treatment at the referring facility and at the regional hospital

\begin{tabular}{|c|c|c|}
\hline Variable & $\begin{array}{l}\text { Referring facility } \\
(N=55)\end{array}$ & $\begin{array}{l}\text { Regional hospital } \\
(N=58)\end{array}$ \\
\hline \multicolumn{3}{|l|}{$\begin{array}{l}\text { Blood pressure levels } \\
\text { (mmHg), mean (SD); range }\end{array}$} \\
\hline Systolic & $167.4(27.2) ; 100-231$ & 151.9 (24.8); $100-211$ \\
\hline Diastolic & 104.2 (22.9); 53 - 196 & $87.4(15.4) ; 54-124$ \\
\hline GCS, mean (SD); range & $13(2) ; 8-15$ & $13(2) ; 7-15$ \\
\hline \multicolumn{3}{|l|}{ Level of consciousness, $n$} \\
\hline Conscious & 24 & 28 \\
\hline Semi-conscious & 12 & 15 \\
\hline Restless & 16 & 11 \\
\hline Unconscious & 6 & 4 \\
\hline $\mathrm{MgSO}_{4}, n$ & 58 & 58 \\
\hline Diazepam/clonezepam, $n$ & 19 & 4 \\
\hline No antihypertensive, $n$ & 9 & 5 \\
\hline Single antihypertensive, $n$ & 17 & 27 \\
\hline Nifedipine, $n$ & 31 & 16 \\
\hline Methyldopa, $n$ & 39 & 52 \\
\hline Labetalol (IV), $n$ & 2 & 1 \\
\hline \multicolumn{3}{|l|}{$\begin{array}{l}\text { Two antihypertensive } \\
\text { agents, } n\end{array}$} \\
\hline Nifedipine + methyldopa & 23 & 21 \\
\hline \multicolumn{3}{|l|}{ Diuretics, $n$} \\
\hline Furosemide & 3 & 3 \\
\hline $\begin{array}{l}\text { Steroids for cerebral } \\
\text { oedema, } n\end{array}$ & 0 & 17 \\
\hline GCS = Glascow coma scale. & & \\
\hline
\end{tabular}


used from the referring facility to the base hospital included ambulance $(n=50,86.2 \%)$ and helicopter $(n=3,5.2 \%)$. The mean time taken for doctor to see patient on arrival was 10 (SD 72.2) (range 5 - 255) minutes; the longest time was 255 minutes (almost 4.5 hours).

The mean waiting time for ambulance transport to referring health facility was 148 minutes ( 2.5 hours). The mean time taken for the patient to reach the regional hospital was 153 minutes from the initial call to referral hospital, and the duration was as long as 435 minutes, i.e. almost 7 hours. Five patients who required rapidacting antihypertensive agents did not receive them, with systolic blood pressure ranging from 173 to $200 \mathrm{mmHg}$ and diastolic from 113 to $123 \mathrm{mmHg}$. They also did not receive any long-acting antihypertensive agents. Five patients did not need any hypertension treatment; of these 5, only 1 patient was not monitored while awaiting an ambulance for transfer to the regional hospital. The blood pressure values in these 5 were $<140 / 90 \mathrm{mmHg}$. All patients had their urine retested for protein at the base hospital and all had proteinuria of $1+$ and greater.

Table 4 shows the mode of delivery and neonatal outcomes, and maternal complications are shown in Table 5.

The maternal death occurred in an unbooked patient who was initially seen at a district hospital with a low GCS and for whom there was considerable delay in interfacility transport, leading to a cerebrovascular accident and multi-organ failure.

\section{Avoidable factors}

Avoidable factors identified were administrative-, health-workerand patient-related factors (Table 6). The major administrative problem was inefficient emergency transport services. This was a problem for $32.7 \%(n=18)$ of the 55 patients referred.

Table 4. Mode of delivery and neonatal outcome

\begin{tabular}{|c|c|}
\hline & $n(\%)^{*}$ \\
\hline \multicolumn{2}{|l|}{ Mode of delivery } \\
\hline Vaginal & $2(3.4)$ \\
\hline Instrumental vaginal & $2(3.4)$ \\
\hline Caesarean & $54(93.1)$ \\
\hline Regional anaesthesia (spinal) & $23(44.2)$ \\
\hline General anaesthesia & $29(55.8)$ \\
\hline $\begin{array}{l}\text { Gestational age at delivery (weeks), } \\
\text { mean (SD); range }\end{array}$ & $33.9(3.9) ; 26-42$ \\
\hline \multicolumn{2}{|l|}{ Neonatal outcome } \\
\hline Live births & $48(82.8)$ \\
\hline Stillbirths & $5(8.6)$ \\
\hline Early neonatal deaths & $5(8.6)$ \\
\hline Birth weight (g), mean (SD); range & $2239.3(667.5) ; 850-3420$ \\
\hline \multicolumn{2}{|l|}{ Neonatal complications } \\
\hline Hypoxic ischaemic encephalopathy & $9(15.5)$ \\
\hline Transient tachypnoea of a newborn & $5(8.6)$ \\
\hline Asphyxia & $1(1.6)$ \\
\hline Congenital sepsis & $5(8.6)$ \\
\hline Hyaline membrane disease & $1(1.6)$ \\
\hline Stay in nursery (days), mean (SD); range & $6.7(9.3) ; 1-32$ \\
\hline *Unless otherwise stated. & \\
\hline
\end{tabular}

\section{Discussion}

This clinical audit of patients with eclampsia identified a wide range of administrative-, health-worker- and patient-related factors prior to transfer to the regional hospital. Although it is impossible to state with any certainty how many severe maternal morbidities might have been avoided through focused action, the presence of at least one administrative-related problem in over $60 \%$ of the cases suggests that serious weaknesses in the healthcare system are contributing to the burden of adverse maternal and neonatal outcomes in these rural health districts. At the district hospitals and clinics, the average time taken for doctors to attend to patients was 10 minutes but there was a wide range (5 - 255 minutes). This time duration may have led to delay in initiation of full emergency care as advocated in the Maternity Care Guidelines for Clinics and District Hospitals. ${ }^{[4]}$

Although it is heartening to know that all patients received magnesium sulphate at the referring institutions, a proportion of patients did not have rapid-acting antihypertensive agents prescribed. This is worrying because the SMR (2011 - 2013) indicates that over 50\% of the maternal deaths due to eclampsia are due to cerebral haemorrhage and oedema. ${ }^{[3]}$ Lowering of sustained severe acute hypertension in pregnancy therefore warrants judicious use of rapid-acting antihypertensive agents as immediate management. ${ }^{[4-8]}$ It is plausible that some health professionals are of the view that magnesium sulphate may have antihypertensive properties and that acute lowering of high blood pressure may cause hypotension. If magnesium sulphate has

Table 5. Maternal complications

\begin{tabular}{|c|c|}
\hline & $n(\%)^{\star}$ \\
\hline Maternal death & $1(1.7)$ \\
\hline \multicolumn{2}{|l|}{ Respiratory/cardiac } \\
\hline Pulmonary oedema & $3(5.2)$ \\
\hline \multicolumn{2}{|l|}{ Renal } \\
\hline Renal failure & $2(3.4)$ \\
\hline Renal dysfunction & $17(29.3)$ \\
\hline \multicolumn{2}{|l|}{ Haematological } \\
\hline Disseminated intravascular coagulation (DIC) & $2(3.4)$ \\
\hline HELLP syndrome & $7(12.1)$ \\
\hline \multicolumn{2}{|l|}{ Obstetric haemorrhage } \\
\hline Abruptio placentae & $2(3.4)$ \\
\hline Postpartum haemorrhage & $3(5.2)$ \\
\hline \multicolumn{2}{|l|}{ Neurological } \\
\hline Low GCS $(<12)$ & $12(20.7)$ \\
\hline Confused & $1(1.7)$ \\
\hline Postpartum psychosis & $1(1.7)$ \\
\hline Paresis & $1(1.7)$ \\
\hline Cerebrovascular accident & $1(1.7)$ \\
\hline Restless & $1(1.7)$ \\
\hline \multicolumn{2}{|l|}{ ICU } \\
\hline Admitted & $14(24.1)$ \\
\hline Stay in ICU (days), mean (SD); range & $4(2) ; 1-9$ \\
\hline \multicolumn{2}{|l|}{ Ventilation } \\
\hline Ventilated & $14(24.1)$ \\
\hline Time on ventilator (days), mean (SD); range & $3(2) ; 1-8$ \\
\hline *Unless otherwise stated. & \\
\hline
\end{tabular}


Table 6. Avoidable factors at referral hospital $(N=55)$

\begin{tabular}{ll}
\hline & $\boldsymbol{n}(\%)^{*}$ \\
\hline Transport problem (delay in ambulances) & $18(32.7)$ \\
Arrival time of ambulance at referring facility after contact (min), mean (SD); range & $147.7(95.2) ; 39-410$ \\
Patient arrival time at base hospital (min), mean (SD); range & $152.5(85.6) ; 15-435$ \\
Health-worker-related problems & $5(9.1)$ \\
$\begin{array}{l}\text { Time for doctor to see patient at referring institution (min), mean (SD); range } \\
\text { Patients requiring rapid-acting antihypertensive not prescribed }\end{array}$ & $10(72.2) ;(5-255)$ \\
$\begin{array}{l}\text { Patient-related problems } \\
\quad \text { No antenatal care }\end{array}$ & $5(9.1)$ \\
*Unless otherwise stated. & $10(18.1)$ \\
&
\end{tabular}

antihypertensive properties, this is probably based on its sedative effects. ${ }^{[6-8]}$ Failure to prescribe rapid-acting antihypertensives immediately and not performing prerequisite investigations are factors indicating that clinical protocols are not being followed. Recently, severe hypertension in pregnancy has been reported to be associated with posterior reversible encephalopathy syndrome (PRES) ${ }^{[6]}$ This syndrome is manifested by nausea, vomiting, visual disturbances, altered mental state, convulsions and coma, together with characteristic neuroradiological findings on computed tomography and magnetic resonance imaging of the brain indicating the presence of vasogenic oedema. Brewer et al..$^{\left[{ }^{[6]}\right.}$ found that 46 of 47 cases of eclampsia had neuroradiological features of PRES in the brain. It has been suggested that the use of rapid-acting antihypertensives and magnesium sulphate given promptly may facilitate recovery from PRES, the most common cause of which is severe preeclampsia and eclampsia. ${ }^{[6-8]}$

The study identified that the majority of cases of eclampsia occurred in teenagers and primigravidae $<24$ years of age. This is consistent with similar findings of the SMR. ${ }^{[3]}$ Furthermore, recent data from a regional health facility in an urban setting ${ }^{[9]}$ indicate that the prevalence of pre-eclampsia in all primigravidae admitted over a 1-year period was $12 \%$. These findings suggest that provision of knowledge and access to contraceptive services for adolescents and young women in underprivileged and rural communities is lacking. A recent study which evaluated the contraceptive prevalence rate in a rural area of the Western Cape found a low rate $39.3 \%$ compared with $64.0 \%$ in the rest of SA) of use among women aged 18 - 44 years. These authors recommend that a greater focus be placed on contraceptive services for nulliparous women. ${ }^{[10]}$ The latest SMR has identified contraception as one of the key factors that should be promoted to reduce deaths from $\mathrm{HDP}^{[3]}$

Failures in emergency transport systems have been previously identified as substandard care in the assessment of maternal deaths. ${ }^{[1]}$ In rural areas, this is compounded by poor roads and vast distances between clinics and the base hospital. Our audit identified the long waiting times for ambulances in the study area, and it is possible that if the 'Free State Model' of stationing ambulances at identified clinics is used, it may greatly reduce interfacility transport times. ${ }^{[12]}$

The management of so-called mild to moderate chronic hypertension and mild to moderate pre-eclampsia on an expectant basis is controversial. Expectant management of such patients is associated with greater maternal complications. ${ }^{[13]}$ In our study, four patients with hypertension were managed as outpatients, indicating a failure to follow clinical protocols. Certainly, management of such patients must be carried out by experienced medical officers, and patients seen weekly with results of blood investigations and fetal monitoring by sonar and fetal cardiotocography. In the absence of this, it may be preferable to refer such patients to a regional hospital or to consider the establishment of waiting mothers' areas at district hospitals so that any emergency can be dealt with fairly rapidly. In our audit, patients who required two antihypertensive agents and gestational hypertensives who had pregnancies $>28$ weeks were treated as outpatients. These patients should have been referred according to national guidelines. ${ }^{[4]}$

Our audit also showed that $12 \%$ had HELLP syndrome. These figures were similar to other reports originating from
SA. ${ }^{[5]}$ They imply that platelet counts should be routinely done in all cases of preeclampsia and observational studies suggest that eclamptics with severe hypertension and low platelets are very likely to develop cerebral haemorrhage. ${ }^{[4]}$ Therefore lowering of very high blood pressure in a controlled fashion is critical in the management of severe hypertension, imminent eclampsia and eclampsia if we are to reduce cerebral haemorrhage. ${ }^{[1,2,4]} \quad$ Rapid-acting agents currently available in SA public health facilities include nifidepine (per os) and labetalol. At a clinic level, nifedipine 5 $10 \mathrm{mg}$ tablets should be used. This should lower high blood pressure within 20 30 minutes. ${ }^{[4,5]}$ High blood pressure should be reduced to levels of approximately 110 $140 \mathrm{mmHg}$ systolic and $90-110 \mathrm{mmHg}$ diastolic. Labetalol given intravenously should be the preferred agent at district and regional hospitals. It should be noted that frequent blood pressure monitoring must be continued for at least 24 hours following delivery. ${ }^{[4]}$

Although there was only one maternal death, a sizeable number of women had acute morbidity, including ICU admissions for respiratory ventilation, paresis and renal failure. These may have been prevented by reduced interfacility transport times (Table 6). The caesarean delivery rate in our audit was high. This was also a finding in other reports and forms part of our clinical protocol to 'stabilise' the patient within 2 4 hours and resort to abdominal delivery if the patient is not in labour or unlikely to deliver within 6 - 8 hours. ${ }^{[4,5]}$ It should also be noted that the mean gestational age of the cases of eclampsia in our study was approximately 34 weeks. Induction of labour in such patients with eclampsia generally takes hours with intense monitoring of mother and fetus. This is not possible in most hospitals in SA.

The question of type of anaesthesia for caesarean delivery in eclampsia is controversial. It is, however, worrying that a large proportion of patients requiring caesarean delivery had spinal anaesthesia. The national Maternity Care Guidelines for Clinics and District Hospitals ${ }^{[4]}$ advocate regional anaesthesia for patients with eclampsia who are fully conscious, with blood pressure levels not requiring rapidacting antihypertensive agents and normal platelet counts. Certainly endotracheal intubation may cause further rises in high blood pressure but factors to be taken into 
account prior to regional anaesthesia are a co-operative patient, with platelet accounts above $70000 \times 10^{9} / \mathrm{L}$ and in whom blood pressure levels are stabilised. Most patients in our study did not have GCS recorded at the time of admission to the district hospitals, but previous studies on eclampsia show that most have GCSs of $>14 .{ }^{[5]}$ It is the authors' opinion that if the criteria for regional anaesthesia are fulfilled, it may be preferable to perform epidural anaesthesia and continue the anaesthesia for 12 - 24 hours following delivery to provide pain relief and prevent increases in blood pressure levels.

Recently, there is evidence which shows that ESMOE (Essential Steps in the Management of Obstetric Emergencies) training can improve skills in the management of obstetric emergencies. However, such training must be ongoing, and in district hospitals the use of simulation exercises (fire drills) may greatly assist teamwork training. ${ }^{[14]}$

Our clinical audit did not reveal any cases which were labelled atypical eclampsia. There were however five patients who did not require antihypertensive therapy. These five cases had blood pressure levels of $<140 / 90 \mathrm{mmHg}$ but had significant proteinuria of at least $1+$ or greater at the base hospital and the referring hospital. Reports of atypical eclampsia and pre-eclampsia have been published. Adie and Moodley ${ }^{[15]}$ reported that $8 \%$ of their 162 patients with a diagnosis of eclampsia were atypical, i.e. had low blood pressure levels or no proteinuria, or in whom the onset of the pre-eclampsia syndrome was 'sudden/rapid'. Sibai and Stella ${ }^{[16]}$ also reported on atypical eclampsia, albeit with higher rates, and suggested that patients who have seizures in pregnancy (as long as there are no neurological signs) should be treated as for eclampsia. These patients should then be investigated in the puerperium for underlying cause of the seizures. ${ }^{[15]}$

Overall, our study showed that eclampsia is still a major problem in rural KZN. Healthcare professionals must focus attention on detecting pre-eclampsia in early pregnancy and providing appropriate care, such as lowering of very high blood pressure and timely delivery. Most authorities suggest delivery of women with pre-eclampsia at 38 weeks' gestation and earlier if warranted. ${ }^{[1,2,4]}$
Moreover, the fact that 49 of the 58 patients with eclampsia had antenatal care suggests the need to improve the quality of antenatal care. In addition, interfacility transport should be improved and regular training on the emergency management of eclampsia carried out through 'fire drills' (emergency obstetric simulation training), and most importantly, reproductive health education, especially contraceptive services, must be improved for rural communities.

\section{References}

1. Tranquilli AL, Dekker G, Magee L, et al. The classification, diagnosis and management of hypertensive disorders of pregnancy: A revised statement from the ISSHP. Pregnancy Hypertens 2014;4(2):97-104. DOI: 10.1016/j.preghy.2014.02.001

2. Mol BW, Roberts CT, Thangaratinam S, Magee LA, de Groot CJ, Hofmeyr GJ. Pre-eclampsia. Lancet 2016;387(10022):999-1011. DOI:10.1016/S0140-6736(15)00070-7

3. National Department of Health, South Africa. Saving Mothers Report (2011 - 2013). The 6th Triennial Report of the National Committee on Confidential Enquires into Maternal Deaths. Pretoria: $\mathrm{NDoH}, 2015$.

4. National Department of Health, South Africa. Maternity Care Guidelines for Clinics and District Hospitals. Pretoria: $\mathrm{NDoH}, 2007$.

5. Moodley J, Kalane G. A review of the management of eclampsia: Practical issues. Hyperten Pregnancy 2006;25(2):47-62.

6. Brewer J, Owens MY, Wallace K, et al. Posterior reversible encephalopathy syndrome in 46 of 47 patients with eclampsia. Am J Obstet Gynecol 2013;208(6):468,el-6. DOI:10.1016.j.jojog.2013.02.015.

7. Johnson AC, Tremble SM, Chan SL, et al. Magnesium sulphate treatment reverses seizure susceptibility and decreases neuroinflammation in a rat model of pre-eclampsia. PLoS One 2014;19(11):e11367. DOI:10.1371.journal.pone.0113670

8. Hammer ES, Cipolla MJ. Cerebrovascular dysfunction in pre-eclamptic pregnancies. Curr Hypertens Rep 2015;17(8):64. DOI:10.007/511907-015-0575-8

9. Moodley J, Onyangunga OA, Maharaj NR. Hypertensive disorders in primigravid black South African women: A one-year descriptive study. Hypertens Pregnancy 2016;8:1-7. Epub ahead of print. DOI:10.1080/10641955.2016.1193190

10. Peer N, Morojele N, London L. Factors associated with contraceptive use in a rural area in Western Cape Province. S Afr Med J 2013;103(6):406-412. DOI:10.7196/SAMJ.6201

11. National Department of Health, South Africa. Saving Mothers Report (2008 - 2010). The 5th Triennial Report of the National Committee on Confidential Enquiries into Maternal Deaths. Pretoria: $\mathrm{NDoH}, 2011$.

12. Schoon M. Impact of inter-facility transport on maternal mortality in Free State Province. S Afr Med J 2013;103(8):534. DOI:10/7196/samj.6828

13. Valent AM, DeFranco EA, Salem A, et al. Expectant management of mild pre-eclampsia versus superimposed pre-eclampsia up to 37 weeks. Am J Obstet Gynecol 2015;212(4):515,e1-8 DOI:10.1016/j.ajog.2014.10.1090

14. Frank K, Lombaard HADT, Pattinson RC. Does completion of the Essential Steps in Managing Obstetric Emergencies (ESMOE) training package result in improved knowledge and skills in managing obstetric emergencies? S Afr J Obstet Gynaecol 2009;15(3):94-99.

15. Adie V, Moodley J. Atypical eclampsia. J Obstet Gynecol 2005;25(4):352. DOI:10.1080/ 01443610500119663

16. Sibai BM, Stella CL. Diagnosis and management of atypical pre-eclampsia-eclampsia. Am J Obstet Gynecol 2009;200(5):481,e1-7. DOI:10.1016/-ajog.208.07.048 